\title{
Heat Transfer Efficiency of Turbulent Film Boiling on a Horizontal Elliptical Tube with External Flowing Liquid
}

\author{
Hai-Ping Hu \\ Department of Marine Engineering, National Taiwan Ocean University, Taiwan \\ Email: hphu@ntou.edu.tw
}

Received 17 March 2016; accepted 8 May 2016; published 11 May 2016

Copyright ( 2016 by author and Scientific Research Publishing Inc.

This work is licensed under the Creative Commons Attribution International License (CC BY).

http://creativecommons.org/licenses/by/4.0/

(c) (i) Open Access

\begin{abstract}
Film boiling on a horizontal elliptical tube immersed in external flowing nitrogen liquid is investigated in the present paper. The isothermal wall temperature is high enough to induce turbulent film boiling, and then a continuous vapor film runs upward over the surface. The high velocity of the flowing saturated liquid at the boundary layer is determined by potential flow theory. In addition, the present paper addresses a new model to predict the vapor-liquid interfacial shear on an elliptical tube under forced convection turbulent film boiling. In the results, film thickness and Nusselt number can be obtained under different eccentricity and Froude number. And a comparison between the results of the present study and those reported in previous experimental studies is provided. The results show that there is a good agreement between the present paper and the experimental data.
\end{abstract}

\section{Keywords}

Eccentricity, Elliptical, Interfacial Shear

\section{Introduction}

The pioneering investigator, Bromley [1], conducted the research of film boiling on a horizontal tube. After Bromley's research, many related researches had been reported. In 1966, Nishikawa and Ito [2] analyzed twophase boundary-layer treatment of free-convection film boiling. The theoretical study investigated on film boiling from an isothermal vertical plate and a horizontal cylinder without considering radiative effects. Jordan [3] investigated the laminar film boiling and transition boiling, and the also discussed the separated region. Sakurai et al. [4] presented the pool film boiling on a horizontal cylinder with theoretical solutions. The analytical heat 
transfer model was based on laminar boundary theory including radiation effects. Besides, Huang et al. [5] conducted the research on the forced convection film boiling. They investigated the flow film boiling across a horizontal cylinder with uniform heat flux. The numerical results agreed with experimental data where the wall temperature did not vary a lot around the heater at high heat fluxes.

Laminar film boiling had been widely discussed in published literature, and so has turbulent film boiling. For example, Sarma et al. [6] presented turbulent film boiling with consideration to thermal radiation for the vertical surface. In the research, the assumption of equal shear condition both at the wall and the vapor-liquid interface was reasonable. Later, Sarma et al. [7] presented some theoretical results about the turbulent film boiling on a horizontal isothermal circular cylinder. The analysis compared the theoretical results with previous experimental results, and found that their results were in a good agreement with the experimental data. Hu [8] presented the surface tension effects in boiling heat transfer of cryogenic $\mathrm{LN}_{2}$ on an ellipsoid. However, the study just researched into a simple theoretical model for turbulent film boiling heat transfer on an ellipsoid under a quiescent liquid. Furthermore, Hu [9] investigated the influences of interfacial shear in turbulent film boiling on a horizontal tube with external flowing liquid.

Even though there were many researches about laminar film boiling and turbulent film boiling, there was little publication about the turbulent film boiling on a horizontal elliptical tube which his high velocity liquid was flowing outside. Predicting interfacial shear in a turbulent film boiling system under high velocity liquid was not easy. However, the present paper successfully predicted the vapor-liquid interfacial shear by using Colburn analogy. The present study applied the interfacial shear into the forced balance equation, and then combined the forced balance equation with the energy equation and thermal energy balance equation. At last, both the film thickness and Nusselt number were obtained. Then, the present analysis also included eddy diffusivity, radiation effects and temperature ratio. Finally, a comparison between the results of the present study and those reported in previous experimental studies was provided. It was found that a good agreement exists between the two sets of results.

\section{Formulations}

Consider a horizontal elliptical tube immersed in an up flowing LN2 of the high velocity $u_{\infty}$ at saturated temperature $T_{s}$. The wall temperature $T_{w}$ is assumed high enough to induce turbulent film boiling on the surface of the elliptical tube, and then a continuous film of vapor runs upward over the surface. The physical model and the coordinate system adopted in the present study are shown in Figure 1, where the coordinates is use two-dimensional orthogonal curvilinear coordinate system.

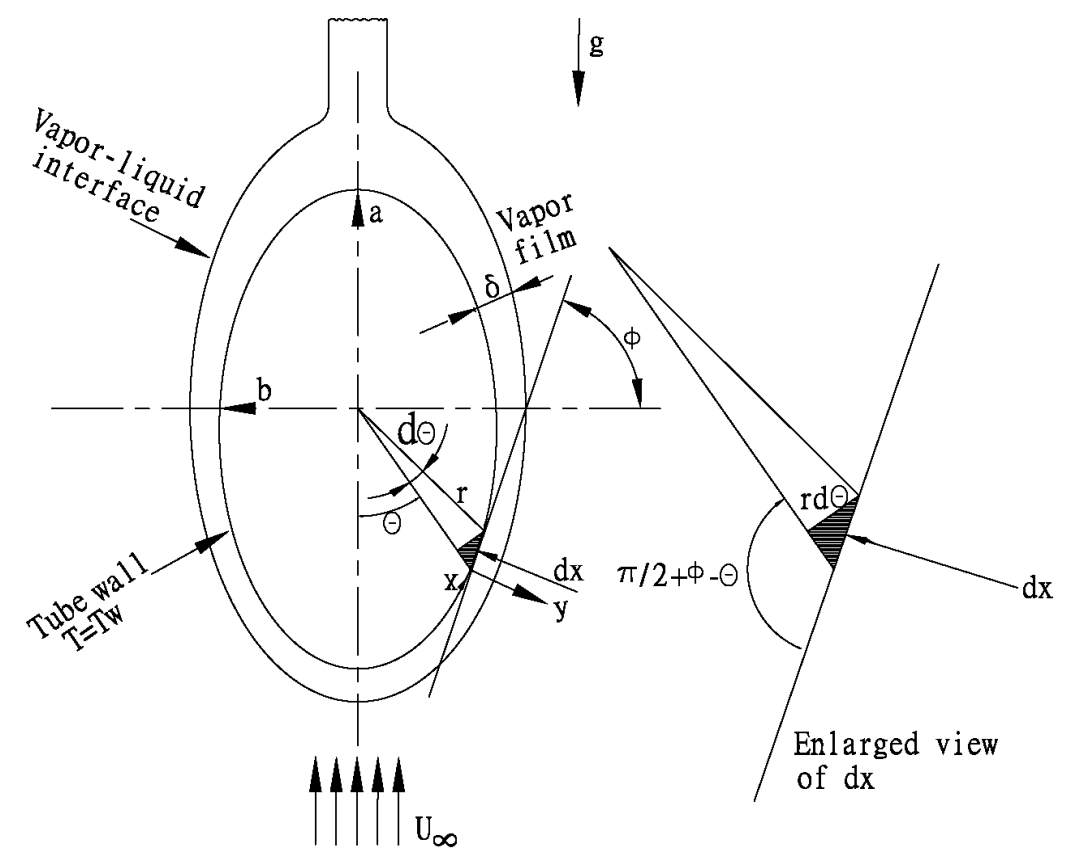

Figure 1. Physical model and coordinate system. 
For thin film flow of turbulent film boiling under the forced convection, the viscosity component and the buoyancy effect are assumed more significant than the inertia force. Then the force balance equation for the vapor film can be expressed as:

$$
\tau_{w}=\tau_{\delta}+g \delta\left(\rho_{l}-\rho_{s}\right) \sin \phi
$$

It is assumed the thickness of vapor film is much thinner than the diameter of the tube ( $\delta \ll D_{e}$ ). And it's further assumed the turbulent conduction term across the vapor layer is more significant than the convective term, and hence the convective term can be neglected. The energy equation can be expressed as:

$$
\frac{\partial}{\partial y}\left\{\left(1+\frac{\varepsilon_{m}}{v} \operatorname{Pr}\right) \frac{\partial T}{\partial y}\right\}=0
$$

The boundary conditions of energy equation under isothermal condition are as follows:

$$
\begin{array}{ll}
T=T_{w} & \text { at } y=0 \\
T=T_{s} & \text { at } y=\delta \text { for } 0 \leq \phi \leq \pi
\end{array}
$$

For a pure substance, the thermal energy balance equation of the vapor film can be expressed as:

$$
\frac{\mathrm{d}}{\mathrm{d} x} \int_{0}^{\delta} \rho_{v} u \mathrm{~d} y=-\left.\frac{k_{w}}{h_{f g}} \frac{\mathrm{d} T}{\mathrm{~d} y}\right|_{y=0}+\frac{\varepsilon \sigma\left(T_{w}^{4}-T_{s}^{4}\right)}{h_{f g}}
$$

The differential arc length for ellipse can be expressed with the following equation:

$$
\mathrm{d} x=I(\phi) \frac{D_{e}}{2} \mathrm{~d} \phi
$$

where

$$
\begin{gathered}
D_{e}=\frac{2 a}{\pi}\left(1-e^{2}\right) \int_{0}^{\pi}\left(1-e^{2} \sin ^{2} \phi\right)^{-3 / 2} \mathrm{~d} \phi \\
I(\phi)=\pi\left(1-e^{2} \sin ^{2} \phi\right)^{-3 / 2} / \int_{0}^{\pi}\left(1-e^{2} \sin ^{2} \phi\right)^{-3 / 2} \mathrm{~d} \phi
\end{gathered}
$$

where $D_{e}$ is an equivalent diameter based on the equal outside surface area, which is compared with circular tubes.

Substitute the $\mathrm{d} x$ into thermal energy balance equation, and (Equation (4)) can be modified as follows:

$$
\frac{\mathrm{d}}{I(\phi) \mathrm{d} \phi} \int_{0}^{\delta} \rho_{v} u \mathrm{~d} y=-\left.\frac{k_{w}}{h_{f g}} \frac{D_{e}}{2} \frac{\mathrm{d} T}{\mathrm{~d} y}\right|_{y=0}+\frac{\varepsilon \sigma D_{e}\left(T_{w}^{4}-T_{s}^{4}\right)}{2 h_{f g}}
$$

In the turbulent region the semi-empirical equation which describes heat transfer in the flow parallel to a moderately curved surface may also be used to describe the heat transfer in the flow parallel to an elliptical surface. Jakob [10] proposed that this situation may be described for any fluid by the following expression:

$$
N u_{l}=C \operatorname{Re}_{l}^{n} \operatorname{Pr}^{1 / 3}
$$

where $C$ is a constant in flow configuration, $C=0.034$.

According to Colburn analogy, the friction factor can be written as the following equation:

$$
\frac{C_{f}}{2}=S t \operatorname{Pr}^{2 / 3}
$$

The mean friction coefficient in the streamwise direction may then be calculated as:

$$
C_{f}=\frac{1}{\pi} \int_{0}^{\pi} f_{\phi} \mathrm{d} \phi
$$

Furthermore, the local friction can be obtained as: 


$$
f_{\phi}=C \pi R e_{l}^{n-1} \sin \phi
$$

The turbulent boundary layer exerts a friction force on the liquid-vapor boundary. The shear stress is estimated by considering the external flowing liquid across the surface of the tube when there is no vapor film on the surface. The local shear stress is defined as:

$$
\tau_{\delta}=f_{\phi}\left(\frac{1}{2} \rho_{l} u_{l}^{2}\right)
$$

According to potential flow theory, when the uniform liquid flow of velocity $u_{\infty}$ passing a tube, the liquid velocity at the edge of the boundary is as follows:

$$
u_{e}=u_{\infty}\left(1+\sqrt{1-e^{2}}\right) \sin \phi
$$

Combining Equations (12)-(14), the local shear stress can be expressed as:

$$
\tau_{\delta}=\frac{1}{2} \pi C \rho_{l} u_{\infty}^{2} R e_{l}^{n-1}\left(1+\sqrt{1-e^{2}}\right)^{2} \sin ^{3} \phi
$$

Incorporating the interfacial vapor shear stress $\tau_{\delta}$ given by Equation (15) into the elemental forced balance equation enables Equation (1) to be rewritten in the following form:

$$
\tau_{w}=2 c \pi \rho_{l} u_{\infty}^{2} R e_{l}^{n-1} \frac{\left(1+\sqrt{1-e^{2}}\right)^{2}}{4} \sin ^{3} \phi+g \delta\left(\rho_{l}-\rho_{s}\right) \sin \phi
$$

The forced balance equation Equation (17) yields the following dimensionless equation:

$$
R_{e}^{* 3}=\frac{\left(1+\sqrt{1-e^{2}}\right)^{2}}{4} R_{e}^{*} \varphi F^{\frac{n+1}{2}} \sin ^{3} \phi+\delta^{+} \sin \phi
$$

It's further assuming the pressure across the boundary layer is constant and the density variation across the boundary layer is given by the following equation:

$$
\rho T=\rho_{w} T_{w}=\rho_{s} T_{s}
$$

The energy equation Equation (2) yields the following dimensionless energy equation:

$$
\frac{\mathrm{d}}{\mathrm{d} y^{+}}\left[\left(1+\frac{\varepsilon_{m}}{v_{s}} \frac{P r}{\mu^{+}\left(T^{+}\right)\left(1+T^{+}\left(T_{r}-1\right)\right)}\right) \frac{\mathrm{d} T^{+}}{\mathrm{d} y^{+}}\right]=0
$$

The dimensionless boundary conditions of Equation (19) are:

$$
\begin{aligned}
& \text { (1) at } y^{+}=0 ; T^{+}=1 \\
& \text { (2) at } y^{+}=\delta^{+} ; T^{+}=0
\end{aligned}
$$

where the absolute viscosity equation $\mu^{+}$in dimensionless energy equation Equation (19) is expressed as the vapors of liquid nitrogen at the saturation temperature corresponding to a system pressure under $1 \mathrm{~atm}$. i.e.

$$
\mu^{+}=\frac{\mu}{\mu_{s}}=2.656-3.804\left(\frac{T}{T_{s}}\right)+2.148\left(\frac{T}{T_{s}}\right)^{2}
$$

Besides, the thermal energy balance equation Equation (8) can be rewritten in dimensionless form as follows:

$$
\begin{aligned}
& \frac{\mathrm{d}}{I(\phi) \mathrm{d} \phi} \int_{0}^{\delta^{+}} \frac{u^{+}}{1+T^{+}\left(T_{r}-1\right)} \mathrm{d} y^{+} \\
& =T_{r} S\left\{\left.(\operatorname{Tr}-1)\left(\frac{G r}{2}\right)^{\frac{1}{3}}\left(R_{e}^{* 3}-\frac{\left(1+\sqrt{1-e^{2}}\right)^{2}}{4} R_{e}^{*} \varphi F r^{\frac{n+1}{2}} \sin ^{3} \phi\right)^{1 / 3} k_{w}^{+} \frac{\mathrm{d} T^{+}}{\mathrm{d} y^{+}}\right|_{y^{+}=0}+N R\left(T_{r}^{4}-1\right)\right\}
\end{aligned}
$$


where the absolute conductivity equation $k^{+}$in thermal energy balance equation Equation (22) is expressed as the vapors of liquid nitrogen the saturation temperature corresponding to a system pressure under $1 \mathrm{~atm} .:$

$$
k^{+}=\frac{k}{k_{s}}=236.1-811.5\left(\frac{T}{T_{s}}\right)+1045.4\left(\frac{T}{T_{s}}\right)^{2}-596.2\left(\frac{T}{T_{s}}\right)^{3}+127.2\left(\frac{T}{T_{s}}\right)^{4}
$$

Furthermore, the dimensionless thermal energy balance equation Equation (22) requires the velocity profile $u^{+}$in the vapor film. And $u^{+}$can be obtained by following equation:

$$
\frac{\mathrm{d} u^{+}}{\mathrm{d} y^{+}}=\frac{1-2 \frac{y^{+}}{\delta^{+}}}{\frac{T}{T_{s}} \mu^{+}\left(T^{+}\right)\left[1+\frac{\varepsilon_{m}}{v_{s}} \frac{1}{\mu^{+}\left(T^{+}\right)\left(1+T^{+}\left(T_{r}-1\right)\right)}\right]}
$$

The boundary condition is:

$$
u^{+}=0, y^{+} / \delta^{+}=0 \text { at } y^{+}=0
$$

The eddy diffusivity distribution presented by Kato et al. [11] is expressed as:

$$
\frac{\varepsilon_{m}}{v_{s}}=0.4 y^{+}\left[1-\exp \left(-0.0017 y^{+2}\right)\right]
$$

The heat transfer of turbulent film boiling can be given by the following equation:

$$
h\left(T_{w}-T_{s}\right)=-\left.k_{w} \frac{\mathrm{d} T}{\mathrm{~d} y}\right|_{y=0}+\sigma \varepsilon\left[T_{w}^{4}-T_{s}^{4}\right]
$$

Obviously, the local Nusselt number can be expressed as:

$$
N u=-\left.k_{w}^{+} R^{*} G r^{1 / 3} \frac{\mathrm{d} T^{+}}{\mathrm{d} y^{+}}\right|_{y^{+}=0}+2 N R\left(\frac{T_{r}^{4}-1}{T_{r}-1}\right)
$$

The mean Nusselt number for the entire surface of the tube can be written as:

$$
N u_{m}=\frac{1}{\pi} \int_{0}^{\pi}\left[-\left.k_{w}^{+} R_{e}^{*} G r^{1 / 3} \frac{\mathrm{d} T^{+}}{\mathrm{d} y^{+}}\right|_{y^{+}=0}+2 N R\left(\frac{T_{r}^{4}-1}{T_{r}-1}\right)\right] \mathrm{d} \phi
$$

\section{Numerical Method}

The dimensionless governing Equations (17), (22)-(26) and (28), (29) subject to the relevant boundary conditions given can be used to estimate $\delta^{+}, R_{e}^{*}$ and $\mathrm{Nu}$ for the vapor film by means of the following procedures by using $\mathrm{C}^{++}$:

1) Suitable dimensionless parameters, such as $e, T_{r}, S, N R, F r$ and $G r$ are specified.

2) The boundary conditions of velocity and temperature are as follows:

$$
\begin{aligned}
\text { at } y^{+} & =0 ; T^{+}=1, u^{+}=0, \mu^{+}=2.656-3.804 T_{r}+2.148 T_{r}^{2} \\
k^{+} & =236.1-811.5 T_{r}+1045.4 T_{r}^{2}-596.2 T_{r}^{3}+127.2 T_{r}^{4} \\
\text { at } y^{+} & =\delta^{+} ; T^{+}=0
\end{aligned}
$$

3) Since the $u^{*}$ at the bottom of the tube ( $\phi=0, i=0$ ) is zero, the dimensionless film thickness $\delta^{+}$is also zero $\left(\delta^{+}=\frac{\delta u^{*}}{v}=\frac{\delta 0}{v}=0\right)$. At the next node, i.e. $i=i+1$, the value of $\phi$ is given by $\phi_{i+1}=\phi_{i}+\Delta \phi$, where $\Delta \phi=(\pi / 360)$.

4) Guess an initial value of $\delta^{+}$; substitute Equations (21), (26) into Equation (19) and then get the value of 


$$
\left.\frac{\mathrm{d} T^{+}}{\mathrm{d} y^{+}}\right|_{y^{+}=0}
$$

5) Substitute $\left.\frac{\mathrm{d} T^{+}}{\mathrm{d} y^{+}}\right|_{y^{+}=0}$, Equations (23), (24) and (25) into Equation (22), and get the value of $R_{e}^{* 3}-\frac{\left(1-\sqrt{1-e^{2}}\right)^{2}}{4} R_{e}^{*} \varphi \mathrm{Fr}^{\frac{n+1}{2}} \sin ^{3} \phi$. After calculating, the values of $R^{*}$ can be gotten, and then substitute the values of $R_{e}^{*}$ into Equation (17).

6) The criterion for the accuracy of $\delta^{+}$is assessed by Equation (17), and it can be expressed as the following unequal equation:

$$
\delta^{+}-\frac{R_{e}^{* 3}-\frac{\left(1+\sqrt{1-e^{2}}\right)^{2}}{4} R_{e}^{*} \varphi F^{\frac{n+1}{2}} \sin ^{3} \phi}{\sin \phi} \leq 10^{-6}
$$

If the calculation is a convergence, process the film thickness of next angular position. If the calculation is not a convergence, guess a new thickness and repeat processes (4)-(6).

7) The process above is repeated at the next node position, i.e. $\phi_{i+1}=\phi_{i}+\Delta \phi$, and then subsequently at all nodes within the range $0 \leq \phi \leq \pi$.

8) The local Nusselt number and mean Nusselt number are then calculated.

\section{Results and Discussion}

Figure 2(a) plots the three-dimensional local velocity distributions in vapor film for $F r=500$. For each angular position $\phi$ on the entire tube surface, it is shown that with an increase in $y^{+}, u^{+}$will increase to a maximum value, and then it will slightly decrease. The results also show that the dimensionless velocity increases with an increasing angular position on the elliptical surface. Figure 2(b) shows the two-dimensional equi-velocities in vapor film for $\mathrm{Fr}=500$. The dimensionless velocity at the wall of the elliptical tube is zero because of the noslip condition and it will increase along the y-direction. This can be apprehended that the velocity will become larger due to the shear stress of vapor-liquid interface under the condition of flowing liquid.

Figure 3(a) shows the velocity distribution of the vapor film on the entire elliptical tube. Figure 3(b) presents the two-dimensional isothermal lines in the vapor film. For the boundary conditions prescribed in the proposed model, the dimensionless temperature on the tube surface and on the vapor-liquid interface are unity and zero respectively. Furthermore, the assumption of the stagnation flow is imposed at the bottom of the tube. As a result, the temperature variation along the vapor film thickness at $\phi=0$ is linear. In addition, the interfacial shear with high velocity liquid, and the effects of turbulence are considered in this work. As the angular position increases, the effects of eddy diffusivity get stronger and the non-linear temperature profile of the vapor film appears.

Figure 4 displays the variation of the dimensionless vapor film thickness on the elliptical tube along $\phi$. Specifically, the film thickness increases continuously from a minimum value at the bottom of the tube $\left(\phi=0^{\circ}\right)$ and reaches its maximum value at the top of the tube $\left(\phi=180^{\circ}\right)$. Besides, according to potential theory, the increase in the eccentricity value will lead to a decrease in the liquid velocity. And the decrease in the liquid velocity will lead to the decrease in heat transfer efficiency and evaporative rate. The former phenomenon will bring about the decrease in the film thickness. Besides, the figure also states the influence of $F r$ on the film thickness. The film thickness will increase when $F r$ values increase. An increase in $F r$ will bring out an increase in the interfacial shear stress and then leads to an increase in the evaporative rate. Consequently, the increase of evaporative rate may cause an increase of the vapor film thickness.

Figure 5 presents the effects of eccentricity on mean Nusselt number under five different Froude numbers. According to the potential flow theory, the larger the eccentricity parameter is, the smaller the liquid velocity and interfacial shear are. Consequently, both the vapor velocity and the mean Nusselt number will decrease. Besides, under the condition of the forced convective film boiling, increasing $\mathrm{Fr}$ will result in an increase of the mean Nusselt numbers. 


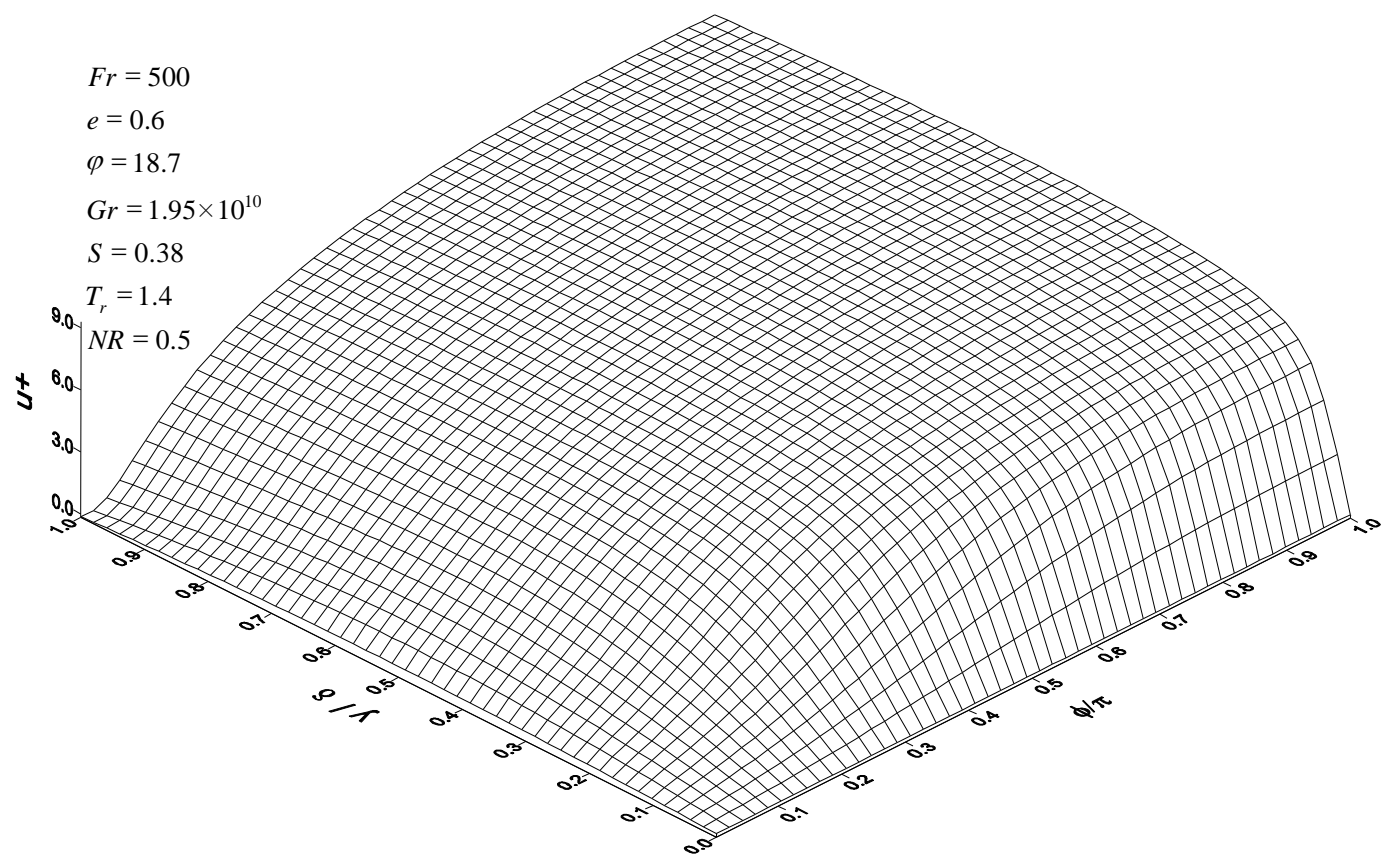

(a)

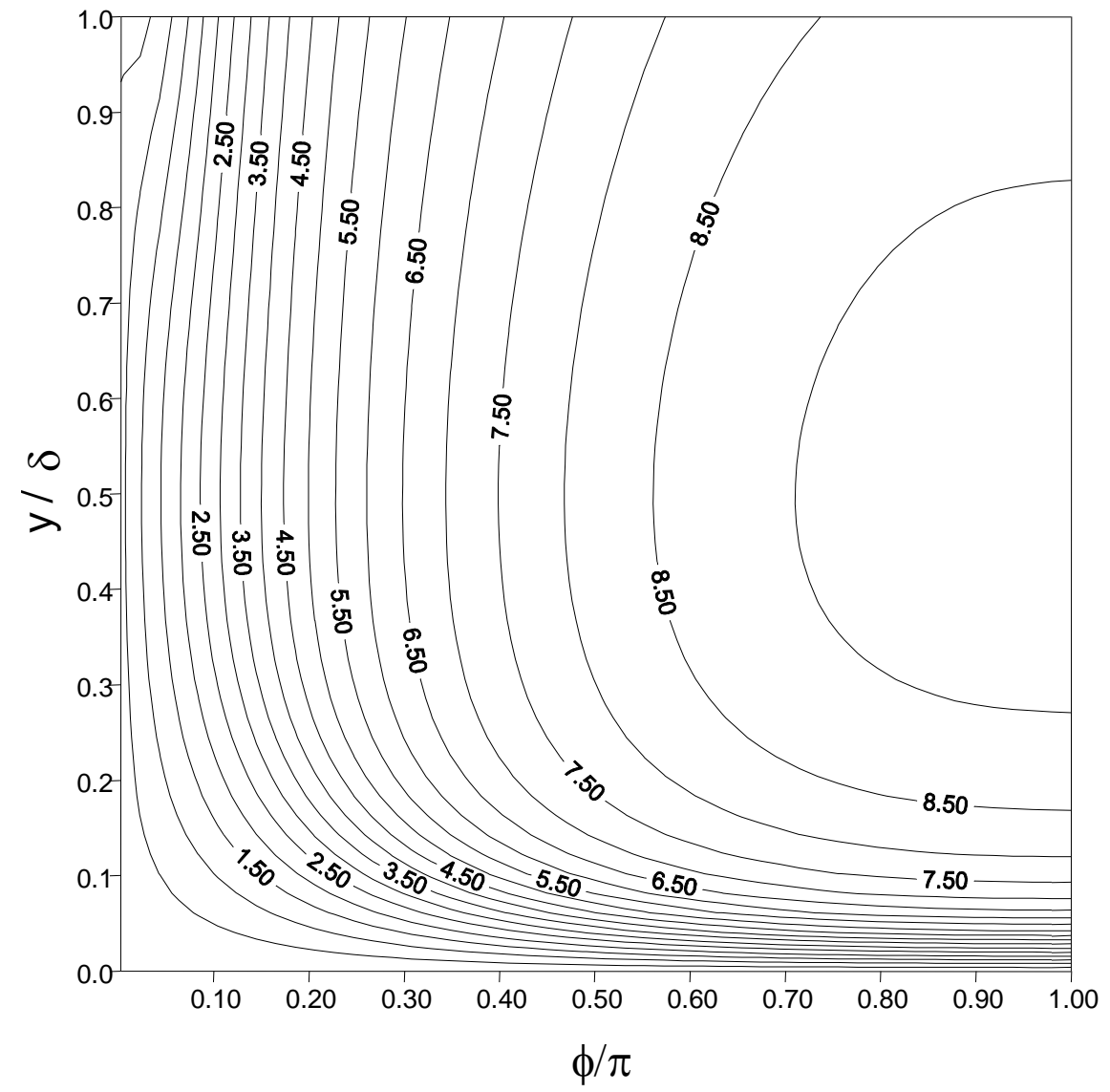

(b)

Figure 2. (a) Local velocity distribution in vapor film. (b) Constant dimensionless velocity lines in vapor film $\left(F r=500, e=0.6, \varphi=18.7, G r=1.95 \times 10^{10}, S=0.38, T_{r}=1.4, N R=0.5\right)$. 


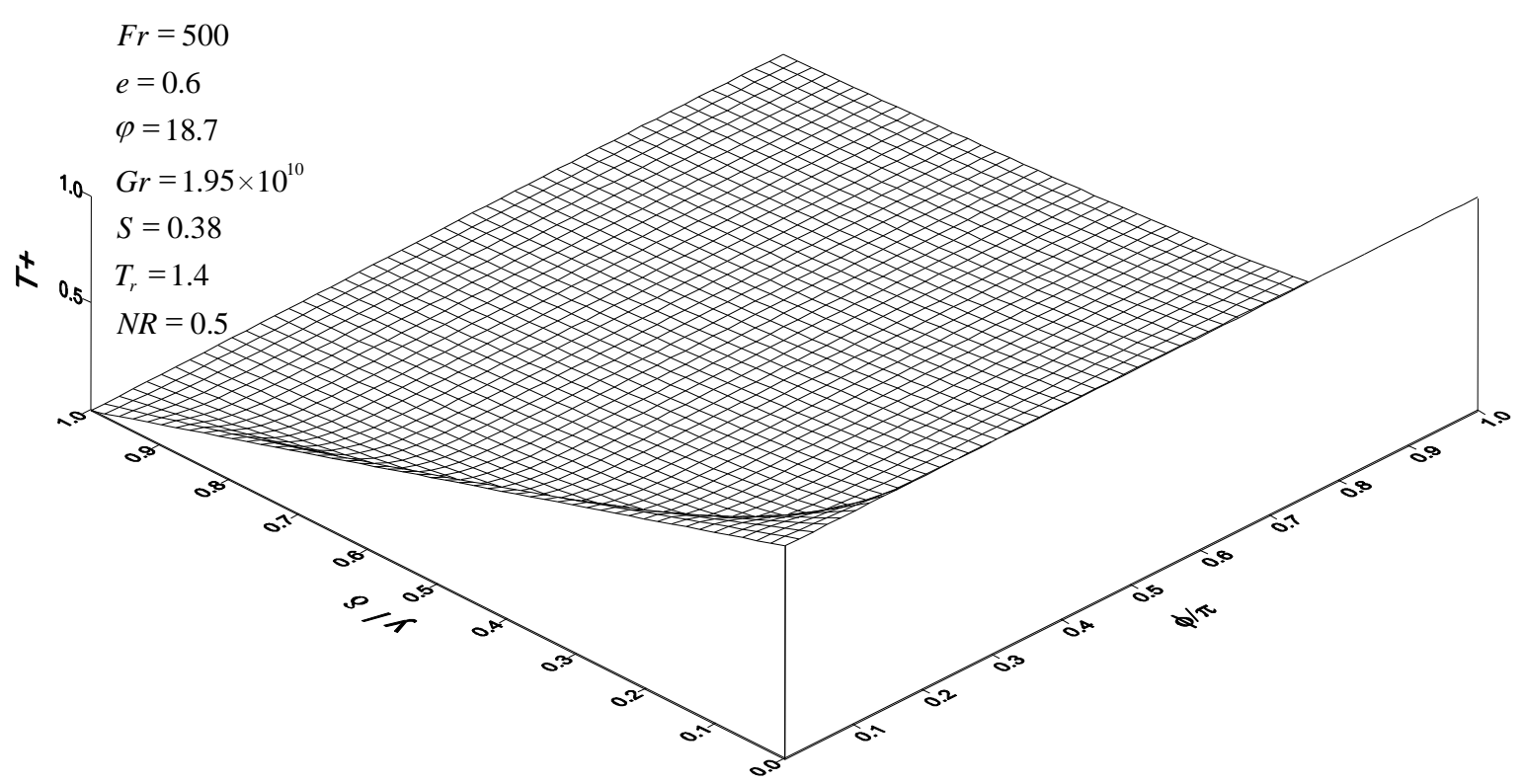

(a)

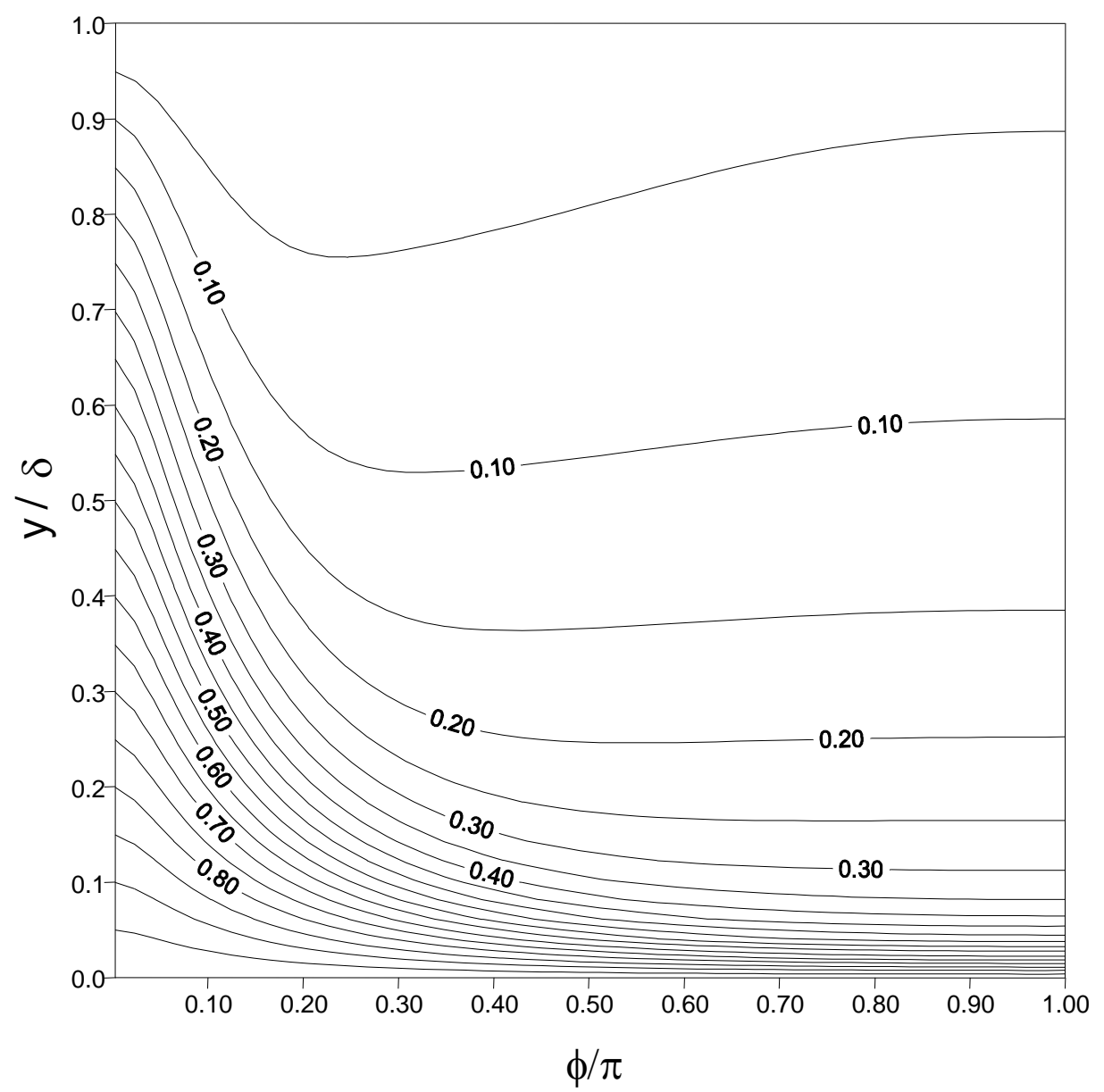

(b)

Figure 3. (a) Local temperature distribution in vapor film. (b) Constant dimensionless temperature lines in vapor film $\left(F r=500, e=0.6, \varphi=18.7, G r=1.95 \times 10^{10}, S=0.38, T_{r}=1.4, N R=0.5\right)$. 


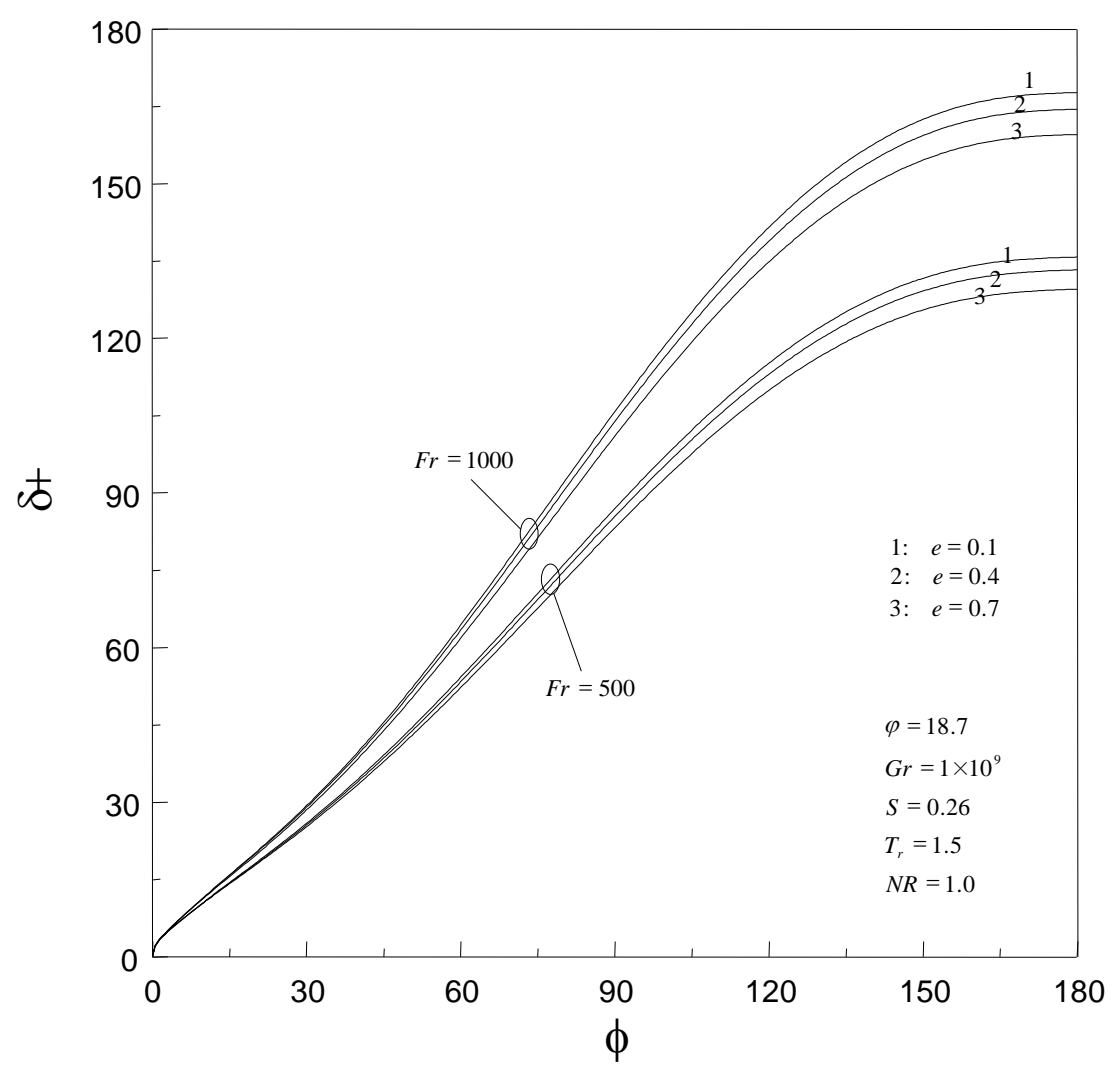

Figure 4. Dimensionless film thickness on tube surface.

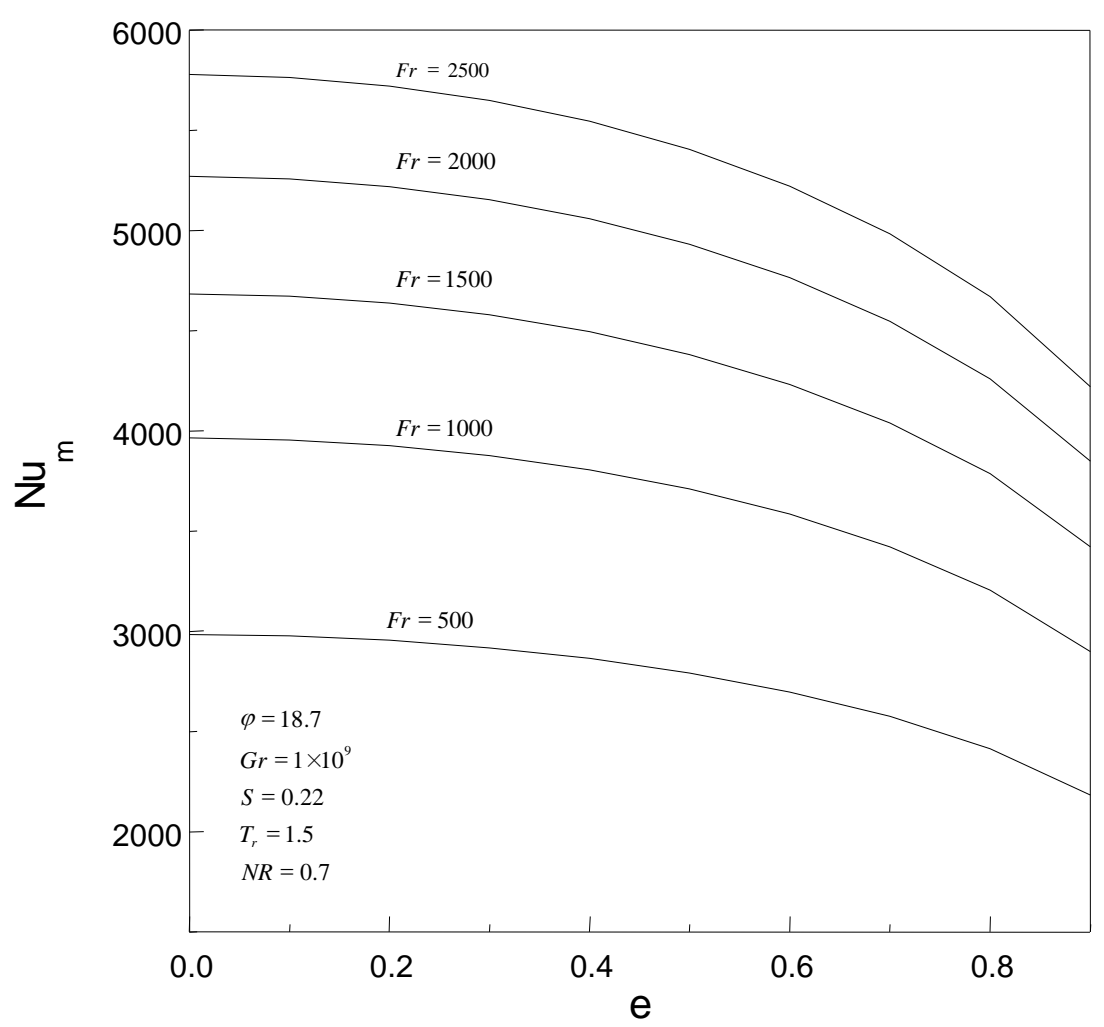

Figure 5. Effects of the eccentricity parameter on mean Nusselt number. 
Figure 6 presents the relationship between the mean Nusselt number and the Froude numbers for five values of Grashof number. The figure shows the results of the forced convection film boiling. A higher Froude number will bring an increase in the mean Nusselt. Besides, the Grashof number $\mathrm{Gr}$ is also one of the dominant factors, and therefore increasing the Grashof number will bring out an increase in the mean Nusselt.

To validate the present model, a comparison is made between this work and previous studies for different cases. For this reason, a modified Rayleigh number is introduced as $R a=\frac{D^{3}\left(\rho_{l}-\rho_{s}\right) g}{\mu_{s}^{2}} \rho_{s} \frac{C_{p} \mu}{k}\left[0.5+\frac{h_{f g}}{C_{p} \Delta T}\right]$ which can be further nondimensionalized in the form of $R a=\operatorname{Gr} \operatorname{Pr}\left[0.5+\frac{1}{S\left(T_{r}-1\right)}\right]$. Figure 7 depicts the effects of $R a$ on the mean Nusselt numbers on an elliptical tube under $e=0$ with special case of a tube subject to turbulent film boiling. It shows that the mean Nusselt number of the present study has a good agreement with previous experimental data [12] under the condition of quiescent liquid (i.e. $\mathrm{Fr}=0$ or $u_{\infty}=0$ ). Besides, $N u_{m}$ increases with $R a$ at fixed radiation parameter. The increase in the radiation parameter, conceivably, will bring out an increase in the mean Nusselt number at a given $R a$.

Figure 8 shows the correlation of Rayleigh number and mean Nusselt number under five different Froude number. According the figure, the increase the Rayleigh number will bring out the increase the mean Nusselt number. Besides, the larger the Froude number will also increase the mean Nusselt number.

\section{Conclusions}

The following conclusions can be drawn from the results of the present theoretical study:

1) With the help of Colburn analogy, the present research successfully predicts the shear stress of the vaporliquid interface in a film boiling system under liquid of high velocity on an elliptical tube.

2) The increase in the eccentricity parameter of the elliptical tube will lead to a decrease in the mean Nusselt number. Besides, turbulent film boiling under the external flowing liquid with high velocity, the increase in both the Froude number and Grashof number will bring out an increase in the mean Nusselt number.

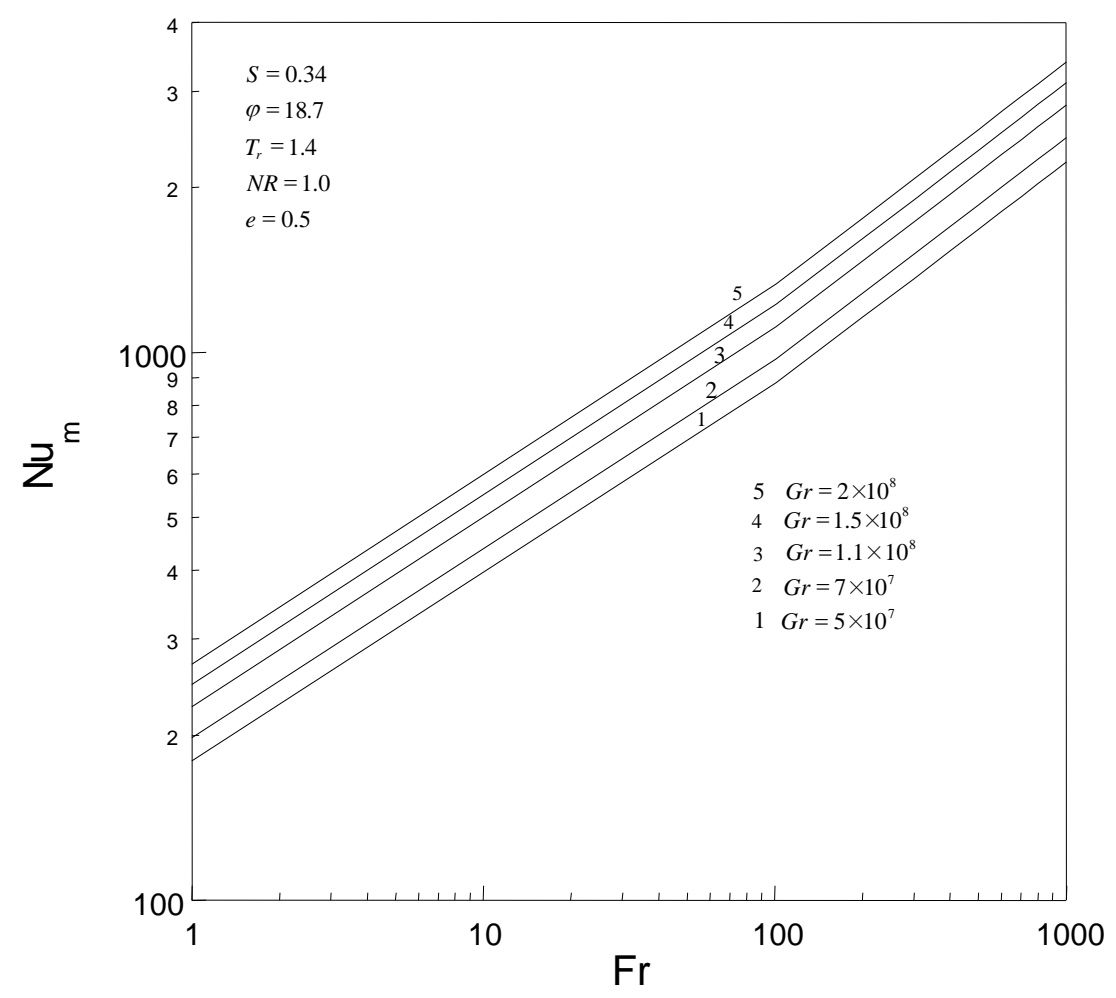

Figure 6. Effects of the Froude number on mean Nusselt number. 


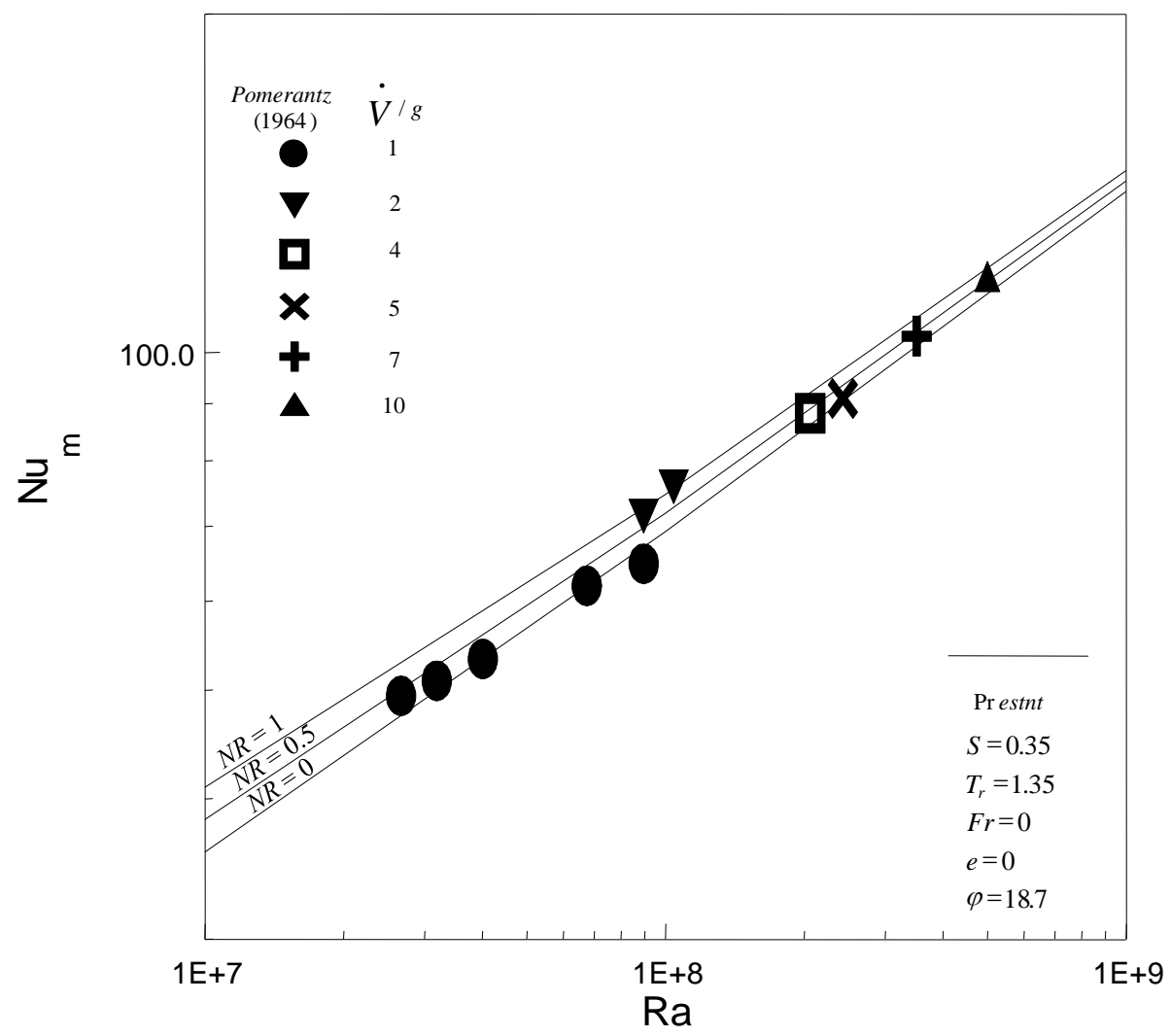

Figure 7. Comparison of the present results with previous data.

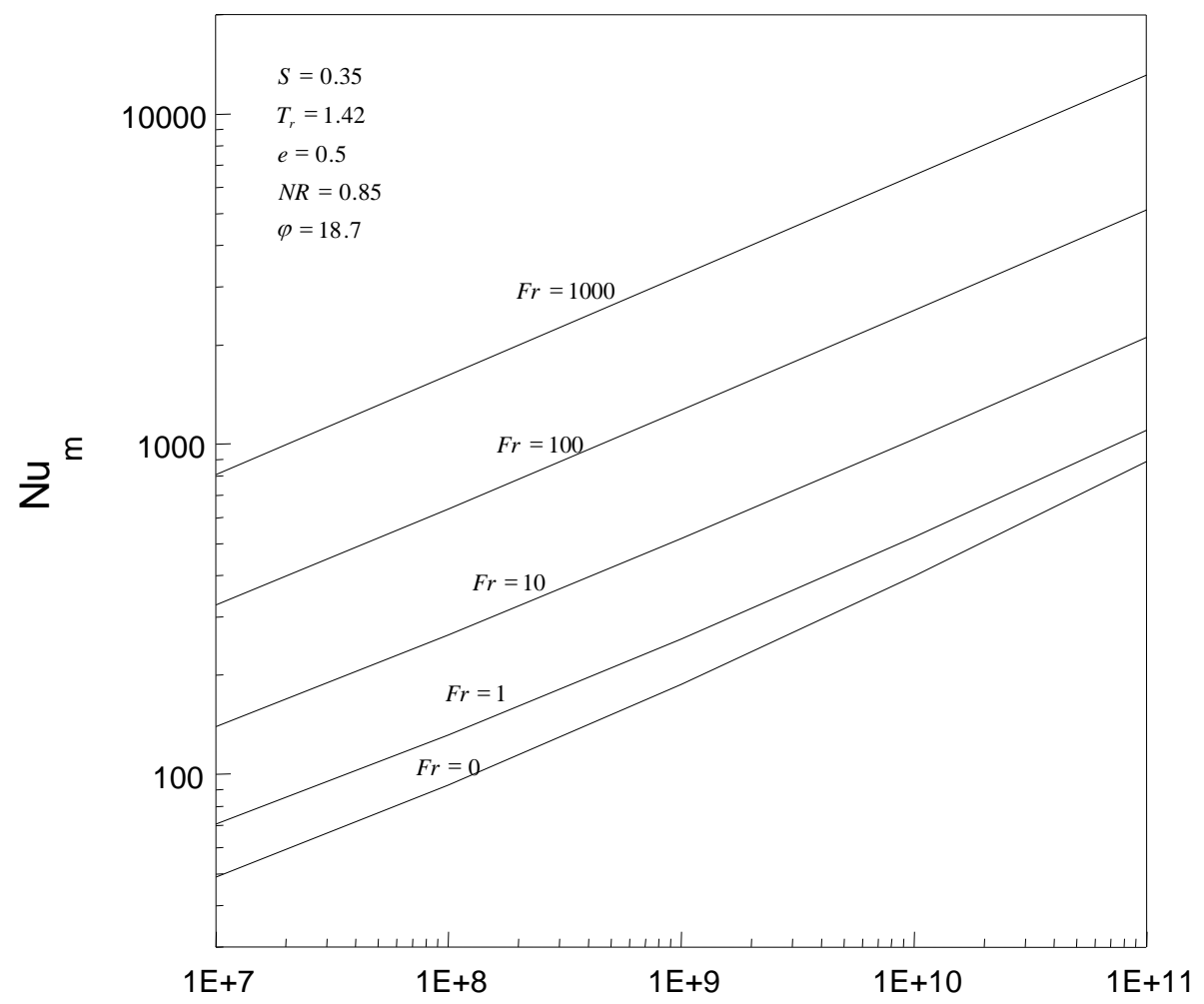

Figure 8. Effects of the $R a$ on mean Nusselt number. 
3) The present paper includes interfacial shear, radiation effects, temperature ratio, eddy diffusivity and thermal properties of temperature dependent. It can predict the forced convection turbulent film boiling more exactly. Besides, under the condition of free convection film boiling, it shows a good agreement between the present result and the previous experimental studies.

\section{Acknowledgements}

The authors gratefully acknowledge the support provided to this projects by the Ministry of Science and Technology of Taiwan under Contract Number MOST 104-2221-E-019-052.

\section{References}

[1] Bromley, L.A. (1950) Heat Transfer in Stable Film Boiling. Chemical Engineering Progress, 46, 221-227.

[2] Nishikawa, K. and Ito, T. (1966) Two-Phase Boundary-Layer Treatment of Free Convection Film Boiling. International Journal of Heat and Mass Transfer, 9, 109-115.

[3] Jordan, D.P. (1968) Film and Transition Boiling. Advances in Heat Transfer, 5, 55-128. http://dx.doi.org/10.1016/S0065-2717(08)70129-1

[4] Sakurai, A., Shiotsu, M. and Hata, K.A. (1990) General Correlation for Pool Film Boiling Heat Transfer from a Horizontal Cylinder to Subcooled Liquid: Part 1-A Theoretical Pool Film Boiling Heat Transfer Models Including Radiation Contributions and Its Analytical Solution. Journal of Heat Transfer, 112, 430-440. http://dx.doi.org/10.1115/1.2910396

[5] Huang, L. and Witte, L.C. (1995) Forced Convection Film Boiling Heat Transfer around Horizontal Cylinders in Highly Subcooled. ASME/JSME Thermal Engineering Conference, 2, 315-322.

[6] Sarma, P.K., Rao, V.D. and Bergles, A.E. (1997) Turbulent Film Boiling on a Horizontal Cylinder-Effect of Temperature Dependent. Energy Conversion and Management, 38, 1135-1144. http://dx.doi.org/10.1016/S0196-8904(96)00143-4

[7] Sarma, P.K., Subrahmanyam, T., Rao, V.D. and Bergles, A.E. (2001) Turbulent Film Boiling on a Horizontal Cylinder. International Journal of Heat and Mass Transfer, 44, 207-214. http://dx.doi.org/10.1016/S0017-9310(00)00061-2

[8] Hu, H.P. (2008) An Analysis of Turbulent Film Boiling on a Sphere with Variable Wall Temperature. Proceedings of the Institution of Mechanical Engineers, Part C: Journal of Mechanical Engineering Science, 222, 1515-1521. http://dx.doi.org/10.1243/09544062JMES943

[9] Hu, H.P. (2015) Influences of Interfacial Shear in Turbulent Film Boiling on a Horizontal Tube with External Flowing Liquid. Engineering, 7, 754-764. http://dx.doi.org/10.4236/eng.2015.711066

[10] Jakob, M. (1949) Heat Transfer. John Wiley \& Sons, New York.

[11] Kato, H., Shiwaki, N.N. and Hirota, M. (1968) On the Turbulent Heat Transfer by Free Convection from a Vertical Plate. International Journal of Heat and Mass Transfer, 11, 1117-1125. http://dx.doi.org/10.1016/0017-9310(68)90029-X

[12] Pomerantz, M.L. (1964) Film Boiling on a Horizontal Tube in Increased Gravity Fields . Journal of Heat Transfer, 86, 213-219. http://dx.doi.org/10.1115/1.3687099 


\section{Nomenclature}

$a, b$ semimajor, semiminior axis of ellipse

$C_{p} \quad$ specific heat capacity, $(\mathrm{J} / \mathrm{kg} \cdot \mathrm{K})$

$D_{e}$ equivalent circular diameter of elliptical tube (m)

$D_{e}^{+} \quad$ shear Reynolds, $D_{e} u^{*} / v_{s}$

$D_{e}^{*} \quad$ wall shear parameter, $D_{e}^{+} / G r^{1 / 3}$

$e$ eccentricity of ellipse, $\sqrt{1-(b / a)^{2}}$

Fr Froude number, $\frac{u_{\infty}^{2}}{g\left(D_{e} / 2\right)}$

Gr modified Grashof number, $\frac{g D_{e}^{3}}{v_{s}^{2}} \frac{\rho_{l}-\rho_{s}}{\rho_{s}}$

$g$ acceleration due to gravity $\left(\mathrm{m} / \mathrm{s}^{2}\right)$

$h$ heat transfer coefficient, $\mathrm{W} /\left(\mathrm{m}^{2} \cdot \mathrm{K}\right)$

$h_{f g}$ latent heat $(\mathrm{J} / \mathrm{kg})$

$k$ thermal conductivity $(\mathrm{W} / \mathrm{m} \cdot \mathrm{K})$

$k^{+}$dimensionless thermal conductivity, $k(T) / k\left(T_{s}\right)$

$\left.k_{w}^{+} \quad k(T)\right|_{y^{+}=0} / k\left(T_{s}\right)$

$\mathrm{Nu}$ local Nusselt number, $h\left(D_{e} / 2\right) / k_{s}$

$N u_{m}$ mean Nusselt number

$N R$ radiation parameter, $\varepsilon \sigma T_{s}^{3}\left(D_{e} / 2\right) / k_{s}$

$\operatorname{Pr}$ Prandtl number, $C_{p} \mu / k$

$R a$ modified Rayleigh number, $\operatorname{Gr} P r\left[0.5+1 / S\left(T_{r}-1\right)\right]$

$R e_{v}$ Reynolds number of vapor, $\frac{u_{\infty} D_{e}}{v_{v}}$

$R_{e}^{*} \quad D_{e}^{*} / 2$

$S$ heat capacity parameter, $C_{p} T_{s} /\left(h_{f g} P r\right)$

St Stanton number, $\mathrm{Nu} /(\mathrm{RePr})$

$T$ temperature (K)

$T_{r}$ temperature ratio, $T_{w} / T_{s}$

$T^{+}$dimensionless temperature, $\left(T-T_{s}\right) /\left(T_{w}-T_{s}\right)$

$u$ vapor velocity in $x$-direction $(\mathrm{m} / \mathrm{s})$

$u^{*}$ shear velocity, $\sqrt{\tau_{w} / \rho_{s}}$

$u^{+}$dimensionless velocity, $u / u^{*}$

$v$ velocity normal to the direction of flow $(\mathrm{m} / \mathrm{s})$

$\dot{V}$ acceleration due to graviton force $\left(\mathrm{m} / \mathrm{s}^{2}\right)$

$x$ peripheral coordinate (m)

$y$ coordinate measured distance normal to tube surface (m)

$y^{+}$dimensionless distance, $y u^{*} / v_{s}$

\section{Greek Symbols}

$\delta \quad$ vapor film thickness (m) 
$\delta^{+}$dimensionless film thickness, $\delta u^{*} / v_{s}$

$\mu \quad$ absolute viscosity $(\mathrm{kg} / \mathrm{m} \cdot \mathrm{s})$

$\mu^{+}$dimensionless absolute viscosity, $\mu / \mu_{s}$

$v$ kinematic viscosity $\left(\mathrm{m}^{2} / \mathrm{s}\right)$

$\rho$ density $\left(\mathrm{kg} / \mathrm{m}^{3}\right)$

$\tau$ shear stress $\left(\mathrm{N} / \mathrm{m}^{2}\right)$

$\theta$ angle measured from bottom of tube

$\phi \quad$ angle between the tangent to tube surface and the normal to direction of gravity

$\varphi \quad$ interfacial shear parameter, $2^{n} \pi C\left(\frac{v_{s}}{v_{l}}\right)^{n-1}\left(\frac{\rho_{l}-\rho_{s}}{\rho_{s}}\right)^{\frac{1-n}{2}} G r^{\frac{3 n-1}{6}}$

$\varepsilon_{m} \quad$ eddy diffusivity for momentum

$\varepsilon$ emissivity

$\sigma$ Stefan-boltzmann constant, $\mathrm{W} / \mathrm{m}^{2} \cdot \mathrm{K}^{4}$

\section{Subscripts}

$l$ liquid

$s$ vapor at saturation temperature

$v$ vapor

$w$ tube wall

$x \quad \mathrm{x}$-direction

$\delta$ vapor-liquid interface 